OPEN ACCESS

Edited by:

Yuji Morita,

Aichi Gakuin University, Japan

Reviewed by:

Shivani Agarwal,

Northwestern University, USA

Thierry Soldati,

University of Geneva, Switzerland

*Correspondence:

Jin-Town Wang

wangjt@ntu.edu.tw:

Tzu-Lung Lin

f87445101@ntu.edu.tw

tThese authors have contributed equally to this work.

Specialty section:

This article was submitted to

Infectious Diseases,

a section of the journa

Frontiers in Microbiology

Received: 03 June 2015 Accepted: 04 December 2015

Published: 07 January 2016

Citation: Chen $Y-Y$, Yang F-L, Wu S-H, Lin T-L and Wang J-T (2016) Mycobacterium

marinum mmar_2318

and mmar_2319 are Responsible for Lipooligosaccharide Biosynthesis and Virulence Toward Dictyostelium.

Front. Microbiol. 6:1458.

doi: 10.3389/fmicb.2015.01458

\section{Mycobacterium marinum mmar_2318 and $m$ mar 2319 are Responsible for Lipooligosaccharide Biosynthesis and Virulence Toward Dictyostelium}

\author{
Yi-Yin Chen ${ }^{1}$, Feng-Ling Yang ${ }^{2}$, Shih-Hsiung Wu ${ }^{2}$, Tzu-Lung Lin ${ }^{1 *+}$ and \\ Jin-Town Wang ${ }^{1,3 *+}$
}

${ }^{1}$ Department of Microbiology, National Taiwan University College of Medicine, Taipei, Taiwan, ${ }^{2}$ Institute of Biological Chemistry, Academia Sinica, Taipei, Taiwan, ${ }^{3}$ Department of Internal Medicine, National Taiwan University Hospital, Taipei, Taiwan

Resistance to phagocyte killing is an important virulence factor in mycobacteria. Dictyostelium has been used to study the interaction between phagocytes and bacteria, given its similarity to the mammalian macrophage. Here, we investigated the genes responsible for virulence to Dictyostelium by screening 1728 transposon mutants of the Mycobacterium marinum NTUH-M6094 strain. A total of 30 mutants that permissive for Dictyostelium growth were identified. These mutants revealed interruptions in 20 distinct loci. Of the 20 loci, six genes (IosA, mmar_2318, mmar_2319, wecE, mmar_2323 and mmar_2353) were located in the lipooligosaccharide (LOS) synthesis cluster. LOS are antigenic glycolipids and the core LOS structure from LOS-I to LOS-IV have been reported to exist in M. marinum. Two-dimensional thin-layer chromatography (2D-TLC) glycolipid profiles revealed that deletion of mmar_2318 or mmar_2319 resulted in the accumulation of LOS-III and deficiency of LOS-IV. Deletion and complementation of mmar_2318 or mmar_2319 confirmed that these genes both contributed to virulence toward Dictyostelium but not entry and replication inside Dictyostelium. Co-incubation with a murine macrophage cell line J774a.1 or PMA-induced human monocytic cell line THP-1 demonstrated that mmar_2318 or mmar_2319 deletion mutant could grow in macrophages, and their initial entry rate was not affected in J774a.1 but significantly increased in THP-1. In conclusion, although mmar_2319 has been reported to involve LOS biosynthesis in a previous study, we identified a new gene, mmar_2318 that is also involved in the biosynthesis of LOS. Deletion of mmar_2318 or mmar_2319 both exhibits reduction of virulence toward Dictyostelium and increased entry into THP-1 cells.

Keywords: M. marinum, lipooligosaccharide, virulence, macrophage, Dictyostelium

\section{INTRODUCTION}

Mycobacterium marinum can cause a systemic tuberculosis-like infection in fish and other ectotherms, a process that involves persistent growth within macrophages (Mehta et al., 2006; Tarigo et al., 2006; Adams et al., 2011; Dong et al., 2012; Hodgkinson et al., 2012; Yang et al., 2012). In humans, this pathogen typically causes only a localized granulomatous infection on cooler surfaces with rare dissemination (Davis and Ramakrishnan, 2009). Macrophages are a 
first line of defense against bacteria and play a key role in the host's innate immune response to bacterial infection. In addition, bacteria that have developed resistance to phagocytosis or intracellular killing should be more virulent and more likely to succeed at establishing infection. Mycobacteria that successfully infect macrophages survive and replicate in the phagosome by arresting phagosome maturation and acidification (Vergne et al., 2004; Wong et al., 2011) and damaging the phagosomal membrane to cause macrophage necrosis (Skeiky and Sadoff, 2006; Behar et al., 2010).

The mycobacterial possess a unique lipid-rich cell wall that is important in directing host-pathogen interactions and confers resistance to many therapeutic agents (Jarlier and Nikaido, 1990; Daffe and Draper, 1998). During the infection process, free cell wall lipids/glycolipids are contributing to modulation of the host immune system and condition the outcome of the infection (Karakousis et al., 2004; Neyrolles and Guilhot, 2011). Lipooligosaccharides (LOS) are cell surface glycolipids, and have been reported to exist in more than 10 mycobacterial species, including the M. canettii, M. marinum, M. kansasii, and M. gastri (Hunter et al., 1983, 1984; McNeil et al., 1989; Daffe, 1991; Gilleron et al., 1993; Burguiere et al., 2005). All LOS are antigenic compounds containing a $\alpha, \alpha$-trehalose unit, the length and composition of LOS are highly variable between different species by different speciesspecific glycan sequence manner. In $M$. marinum, produces under laboratory conditions, four major LOS structures of increasing size, named LOS-I to LOS-IV, has been previously identified (Burguiere et al., 2005). Loss of LOS results in a rough bacterial colony morphology (Ren et al., 2007; Sarkar et al., 2011), hyper-virulence in zebrafish (van der Woude et al., 2012), reduced biofilm formation, sliding motility, and affect entry rate into macrophages (Ren et al., 2007; Alibaud et al., 2014), inhibition of tumor necrosis factor alpha (TNF- $\alpha$ ) secretion in macrophages (Rombouts et al., 2009); and decreased release of proline-glutamic acid_polymorphic guanine-cytosinerich sequence (PE_PGRS) proteins from the cell surface (van der Woude et al., 2012).

A well-established model system using Dictyostelium discoideum was introduced for studying the interactions between phagocytes and bacteria (Solomon et al., 2003; Harriff and Bermudez, 2009; Alibaud et al., 2011). Dictyostelium, a freeliving amoeba, serves as a macrophage-like system for studying bacteria-host interactions (Solomon et al., 2003). Dictyostelium has also been used to analyze the virulence of different bacterial species, including extracellular or intracellular bacteria, such as Pseudomonas (Cosson et al., 2002; Pukatzki et al., 2002), Yersinia (Vlahou et al., 2009), Vibrio (Pukatzki et al., 2006, 2007), Legionella (Hilbi et al., 2007; Jules and Buchrieser, 2007; Li et al., 2009), Klebsiella (Pan et al., 2011), and Mycobacteria (Pozos and Ramakrishnan, 2004; Hagedorn et al., 2009). Upon infection of Dictyostelium, M. marinum can survive and replicate within intracellular vacuoles, exhibiting a pattern of growth similar to that observed in cultured mammalian macrophages (Hagedorn and Soldati, 2007). Notably, a previous study demonstrated by using a Dictyostelium screening model ( $\leq 1000$ cells) can identify the virulence determinants in M. marinum (Alibaud et al., 2011).

As we report here, we constructed a $M$. marinum mutant library by transposon mutagenesis and used a Dictyostelium screening model to identify genetic loci involved in $M$. marinum virulence. We identified a new gene, mmar_2318, which participates in LOS synthesis and virulence toward Dictyostelium.

\section{MATERIALS AND METHODS}

\section{Bacterial Strains, Cells, and Growth Conditions}

Mycobacterium smegmatis $\mathrm{mc}^{2} 155$ and M. marinum NTUHM6094 (clinically isolated strain from National Taiwan University Hospital) strains were grown at $37^{\circ} \mathrm{C}$ and $32^{\circ} \mathrm{C}$, respectively, in $7 \mathrm{H} 9$ medium supplemented with $10 \%$ oleic acid/albumin/dextrose/catalase (OADC) enrichment and 0.05\% Tween-80. M. marinum is a biosafety level-2 microorganism. The experiments handling the bacteria should follow all appropriate guidelines and regulations. Escherichia coli and Klebsiella aerogenes were grown in Luria broth. Antibiotics were added at the following concentrations when required: kanamycin at $10 \mathrm{mg} / \mathrm{L}$ for M. marinum and $50 \mathrm{mg} / \mathrm{L}$ for E. coli; hygromycin at $50 \mathrm{mg} / \mathrm{L}$ for $M$. marinum and $100 \mathrm{mg} / \mathrm{L}$ for E. coli; and ampicillin at $100 \mathrm{mg} / \mathrm{L}$ for E. coli. D. discoideum AX-2 cells were grown at $20^{\circ} \mathrm{C}$ in HL5 medium (Pan et al., 2011).

\section{Dictyostelium Growth in a Mycobacteria-Phagocytosis Plaque Assay}

The Dictyostelium phagocytosis plaque assay was performed as previously described (Bardarov et al., 1997; Alibaud et al., 2011) with some modifications (Figure 1A). A 1-mL volume of mid-log phase $\left(O D_{600}=0.8-1.2\right)$ M. marinum culture was centrifuged and then resuspended with $800 \mu \mathrm{L}$ of overnightcultured $K$. aerogenes (as a substrate for Dictyostelium when the amoebae were not inhibited by the bacteria) diluted $10^{5}$ fold in normal saline. The bacterial suspension was plated in six-well $(350 \mu \mathrm{L} /$ well $)$ or 24 -well $(50 \mu \mathrm{L})$ plates containing $\mathrm{SM}$ agar (Pan et al., 2011) and then air-dried in a biosafety cabinet for 2 h. D. discoideum (400 cells/plate) was then spotted on top of the bacterial lawn. Phagocytosis plaques generated during $D$. discoideum growth became visible after 6-8 days of incubation at $20^{\circ} \mathrm{C}$.

\section{Generation of $M$. marinum Transposon Mutant Library}

The TM4-derived conditionally replicating phage phAE94 (a kind gift from Dr. William R. Jacobs, Jr., Howard Hughes Medical Institute, USA; Bardarov et al., 1997) carrying the kanamycinresistance transposon Tn5367 (Shin et al., 2006) was propagated in M. smegmatis $\mathrm{mc}^{2} 155$ (Bardarov et al., 1997) and used to infect M. marinum as described previously (Rybniker et al., 2003). 
A

K. aerogenes

(overnight culture, $10^{5} \mathrm{X}$ dilution)

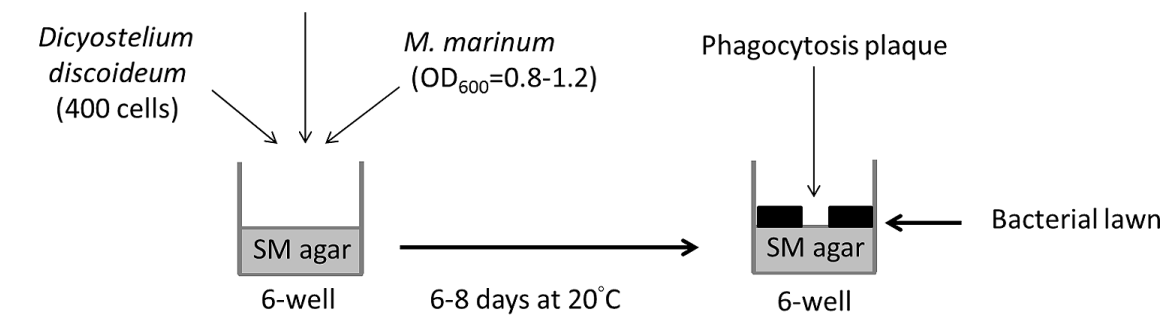

B

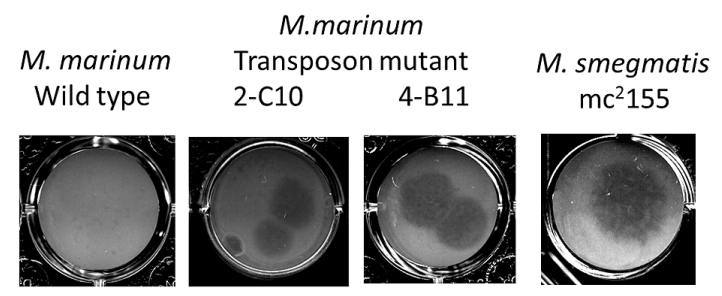

FIGURE 1 | Identification of Mycobacterium marinum genes for virulence using Dictyostelium. (A) Screening method of M. marinum NTUH-M6094 mutant library by Dictyostelium phagocytosis plaque assay. In six-well tissue culture plates containing SM agar, mid-log phase $\left(O D_{600}=0.8-1.2\right)$ cultured $M$. marinum and fresh overnight-cultured Klebsiella aerogenes (diluted $10^{5}$-fold) were mixed in normal saline and then air-dried. Four hundred Dictyostelium cells were then added on the top of the bacterial lawn. The plates were incubated at $20^{\circ} \mathrm{C}$ for $6-8$ days until phagocytosis plaques became visible. (B) Dictyostelium phagocytosis plaques on the M. marinum M6094 wild type two transposon mutants and M. smegmatis. In presence of wild-type M. marinum M6094, Dictyostelium failed to form phagocytosis plaques. In contrast, a clear phagocytosis plaque was observed on bacterial lawn with M. smegmatis (avirulence mycobacteria). Two mutants 2-C10 and 4-B11 permit the formation of a clear phagocytosis plaque on the bacterial lawn.

\section{Identification of Transposon Mutants by Semi-Random Polymerase Chain Reaction}

The insertion site of Tn5367 was determined by semi-random PCR and DNA sequencing as previously described (Chun et al., 1997; Choi et al., 2001; Shin et al., 2006); the primers are listed in Table 1.

\section{Construction of Deletion Mutant}

The gene-deleted fragments $(\Delta 2318$ and $\Delta 2319)$ were generated by using the primer pairs listed in Table 1 and then cloned into a pGEM ${ }^{\circledR}-\mathrm{T}$ easy (Promega) plasmid. The Hyg ${ }^{\mathrm{r}}-\mathrm{lacZ}-\mathrm{sacB}$ cassette of the pGOAL19 plasmid (Addgene Plasmid \#20190; Parish and Stoker, 2000) was digested with PacI and cloned into the PacI site of the resulted plasmid. The vector for gene deletion was transformed into the M. marinum NTUH-M6094 strain according to the established procedures (Larsen et al., 2007), and the $M$. marinum deletion mutant was selected after two rounds of homologous recombination, as previously described (Parish and Stoker, 2000).

\section{Construction of Complementation Strain}

Mycobacterium marinum mmar_2318 (909 bp) and its predicted promoter region (260 bp upstream) were PCR-amplified from genomic DNA using the primer pair 2318-promoterF/2318-R; mmar_2319 (1638 bp) and the M. bovis BCG $h s p 60$ promoter region (250 bp) were PCR-amplified from genomic DNA and pMN402 (a kind gift from Dr. Michael Niederweis at the University of Alabama at Birmingham, USA; Scholz et al., 2000) using the primer pairs 2319-F-hsp60/2319-R and hsp60-F/hsp60-R-2319, respectively. The primer pair hsp60-F and 2319-R was then used to PCR amplify the mmar_2319 gene with the $h s p 60$ promoter region (1872 bp). Those two PCR products were cloned into a blunted HindIII-site of pMN437 (a kind gift from Dr. Michael Niederweis at the University of Alabama at Birmingham, USA; Steinhauer et al., 2010) to create pMm2318::pMN437 and pMm2319::pMN437. The complementation strain $(\Delta 2318:: 2318$ and $\Delta 2319:: 2319)$ was created by transforming the pMm2318::pMN437 or pMm2319::pMN437 plasmid into the $\Delta 2318$ or $\Delta 2319$ strain.

\section{Mycobacterium marinum Lipid Extraction and Analysis}

Mycobacterium marinum polar and apolar lipids were extracted from fresh-cultured $M$. marinum grown on $7 \mathrm{H} 9$ agar plates according to established procedures (Ren et al., 2007). The lipid extract was examined by two-dimensional thin layer chromatography (2D-TLC) (Burguiere et al., 2005). Lipids were visualized by spraying the plates with ceric ammonium molybdate (CAM; $24 \mathrm{~g}\left(\mathrm{NH}_{4}\right)_{6} \mathrm{Mo}_{7} \mathrm{O}_{24} \cdot 4 \mathrm{H}_{2} \mathrm{O}, 0.5 \mathrm{~g}$ ammonium cerium nitrate, $500 \mathrm{~mL} \mathrm{H} \mathrm{H}_{2} \mathrm{O}, 28 \mathrm{~mL} \mathrm{H}_{2} \mathrm{SO}_{4}$ ) followed by gentle charring of the plates. 
TABLE 1 | Primers and plasmids used in this work.

\begin{tabular}{|c|c|c|c|}
\hline Primer name & sequence & Purpose & Reference \\
\hline $\mathrm{TnF}$ & TGCAGCAACGCCAGGTCCACACT & Semi-random PCR & \\
\hline $\operatorname{TnR}$ & CAGAAAGTCGTCAGGTCAGC & Semi-random PCR & \\
\hline HOPS1 & GGCGTAGGAACCTCCATCATC & Semi-random PCR & Bardarov et al., 1997 \\
\hline HOPS2 & CTTGCTCTTCCGCTTCTTCTCC & Semi-random PCR & Bardarov et al., 1997 \\
\hline semi-rand_2-1 & GGCCACGCGTCGACTAGTACNNNNNNNNNNGCAGC & Semi-random PCR & Choi et al., 2001 \\
\hline semi-rand_4 & GGCCACGCGTCGACTAGTAC & Semi-random PCR & Choi et al., 2001 \\
\hline 2318-Ff-F & ATGAGCATCGCGATGCCCGC & $\Delta 2318$ & \\
\hline 2318-Rf-R-Pacl & TТAATTAATCACCGCCTACCTCTTGGCTC & $\Delta 2318$ & \\
\hline 2318-Rf-F & CCTGAATGAGCATTGCCTGTGATGGATGGC & $\Delta 2318$ & \\
\hline 2318-Ff-R & GCCATCCATCACAGGCAATGCTCATTCAGG & $\Delta 2318$ & \\
\hline 2318-promoter-F & GTGCGCTACAAGTTCTAAACC & $\Delta 2318:: 2318$ & \\
\hline 2318-R & CTAATCATCCAGAACTGCTA & $\Delta 2318:: 2318$ & \\
\hline 2319-Rf-R-Pacl & TTAATTAAACGAAGTCATCCTGCCGTC & $\Delta 2319$ & \\
\hline 2319-Rf-F & CTGCGGCGCCCGGATTTCACCGCTCATTCA & $\Delta 2319$ & \\
\hline 2319-Ff-R & TGAATGAGCGGTGAAATCCGGGCGCCGCAG & $\Delta 2319$ & \\
\hline 2319-Ff-F & AGGCGTTAGCTACGTGTCGTC & $\Delta 2319$ & \\
\hline hsp60-F & GGTGACCACAACGACGCGCCC & $\Delta 2319:: 2319$ & \\
\hline hsp60-R-2319 & $\begin{array}{l}\text { GAGAGGAGTCTGTCACATGTATATCTCCTTCTTAAT } \\
\text { TAACTCACCGGT }\end{array}$ & $\Delta 2319:: 2319$ & \\
\hline 2319-F-hsp60 & AGAAGGAGATATACATGTGACAGACTCСTCTCСTCCC & $\Delta 2319:: 2319$ & \\
\hline 2319-R & GTGACAGACTCCTCTCCTC & $\Delta 2319:: 2319$ & \\
\hline Plasmid & Features & & Reference \\
\hline pMN437 & pMN016 derivative, $\mathrm{p}_{\mathrm{smyc}}-\mathrm{gfp}_{\mathrm{m}}{ }^{2+} ; \mathrm{pAL5000}$ origin; $\mathrm{Hyg}^{r}$, & & Steinhauer et al., 2010 \\
\hline pMN402 & $\begin{array}{l}\text { Hyg }^{r} \text {; replicating mycobacterial plasmid with gfp under the } \\
\text { control of the BCG hsp60 promoter }\end{array}$ & & Scholz et al., 2000 \\
\hline pGOAL19 & Hyg $^{r} ; P_{\text {Ag85-lacZ }} P_{\text {hsp60-sacB Pacl cassette vector, amp }}$ & & Parish and Stoker, 2000 \\
\hline
\end{tabular}

\section{Infection of Dictyostelium by M. marinum}

Infection of Dictyostelium was performed as described previously (Arafah et al., 2013).

\section{Infection of J774a.1 or THP-1 Cell Line by M. marinum}

Infection of murine J774a.1 macrophage-like cells as well as human THP-1 monocytic cell line and enumeration of intracellular $M$. marinum $\mathrm{CFU}$ was performed as described previously (Ren et al., 2007). Briefly, a single-cell suspension of fresh cultured M. marinum $\left(O D_{600}=0.8-1.0\right)$ was yield by passage through a $5-\mu \mathrm{m}$ syringe filter. The day before experiment, cell were seeding into 24 well [J774a.1, $10^{5}$ cells/well; THP-1, $10^{6}$ cells/well, and pre-treatment of THP-1 cell with $50 \mathrm{ng} / \mathrm{ml}$ phorbol 12 -myristate 13 -acetate (PMA) for $48 \mathrm{~h}$ ]. The cells were infected with bacteria at a multiplicity of infection (MOI) of 1 for growth assays or MOI of 10 for entry rate assays. A previous study indicated that the difference of entry rate between wild type and mutant will be more prominent under MOI of 10 (Alexander et al., 2004). The infection was allowed to proceed for $3 \mathrm{~h}$ at $32^{\circ} \mathrm{C}$ in $5 \% \mathrm{CO}_{2}$. The extracellular bacteria were removed by washing once with culture medium and incubation in fresh culture medium containing gentamicin $\left(200 \mathrm{mg} / \mathrm{L}, \mathrm{Gibco}^{\oplus}\right)$ for $2 \mathrm{~h}$ at $32^{\circ} \mathrm{C}$. The cells were washed once and incubated with fresh culture medium containing $20 \mathrm{mg} / \mathrm{L}$ gentamicin at $32^{\circ} \mathrm{C}$ in $5 \% \mathrm{CO}_{2}$. On different time point, the infected macrophage monolayers were washed once with culture medium and lysed with $1 \mathrm{~mL}$ of $0.1 \%$ Triton X-100 (Sigma) for $5 \mathrm{~min}$ to release the intracellular mycobacteria. The intracellular bacteria were enumerated by plating serial dilutions on $7 \mathrm{H} 11$ agar plates.

\section{Statistical Analysis}

Data are presented as means \pm standard error of the mean (SEM) form three independent experiments. Statistical significance was assessed by a two-tailed Student's $t$-test using Prism 5 $\left(G r a p h P a d\right.$ Prism $\left.{ }^{\oplus}\right)$ software. $P$-values of $<0.05$ were considered significant.

\section{RESULTS}

\section{Screening Mutants Permissive for Dictyostelium Growth}

We constructed a transposon mutant library of the M. marinum strain NTUH-M6094. A total of 1728 mutants were collected. A Dictyostelium phagocytosis plaque assay (Figure 1A) was used to investigate virulence genes in the M6094 mutant library (Alibaud et al., 2011). As shown in Figure 1B, wildtype M6094 did not allow Dictyostelium (400 cells) to form a phagocytotic plaque on a bacterial lawn. In contrast, a plaque 
was observed on a lawn containing $M$. smegmatis $\mathrm{mc}^{2} 155$ (avirulent mycobacteria). Screening of the entire M6094 mutant library resulted in the identification of 30 transposon mutants that were permissive for Dictyostelium growth; examples of the sensitive isolates (two transposon mutants, 2-C10 and 4B11) are presented in Figure 1B. This phenotype implied that the genes disrupted by the transposon are potentially involved in virulence. The genes interrupted by transposons were determined by semi-random PCR (Chun et al., 1997; Shin et al., 2006) and DNA sequencing (Table 2). The results indicated that 20 genes were disrupted by the transposon, and the locations of the transposon insertion in the 30 mutants were unique.

\section{Defective LOS Biosynthesis in the Deletion Mutant}

Among the 30 attenuated mutants, the transposons of three mutants (4-B11, 4-C3, 16-G9) were inserted into different sites of los A, four mutants (2-A3, 4-E9, 14-D5, 15-D8) into mmar_2318, three mutants (2-E6, 11-G3, 16-F5) into mmar_2319, two mutants $(2-\mathrm{C} 10,2-\mathrm{G} 4)$ into wecE, one mutant into mmar_2323 (10-A11) and one mutant into mmar_2353 (13-B8) (Figure 2). As presented in Table 2 and Figure 2, these six genes (los $A$, mmar_2318, mmar_2319, wecE, mmar_2323, and mmar_2353) are located within a putative LOS biosynthetic gene cluster (mmar_2307 mmar_2405) (Ren et al., 2007; van der Woude et al., 2012). Previous studies reported that losA, mmar_2319, wecE and mmar_2353 are involved in LOS biosynthesis (Domenech et al., 2005; Brodin et al., 2010). Here, two genes, mmar_2318 and mmar_2319, which were identified in several attenuated mutants in this study were chosen for further studies. Deletion mutants ( $\Delta 2318$ and $\Delta 2319)$ and episomal complementation strains $(\Delta 2318:: 2318$ and $\Delta 2319:: 2319)$ were generated accordingly (Figure 3A). The surface polar lipid profiles of wild-type, deletion mutants ( $\triangle 2318$ and $\Delta 2319)$, and complementation strains $(\Delta 2318:: 2318$ and $\Delta 2319:: 2319)$ were examined by $2 \mathrm{D}$-TLC (Figure $3 \mathrm{~B}$ ). We referred to several previous studies to predict the pattern of lipid migration on TLC plate (Alexander et al., 2004; Burguiere et al., 2005; van der Woude et al., 2012; Alibaud et al., 2014). The 2DTLC spots of $\operatorname{los} A:: \mathrm{Tn}$ and wecE::Tn (Supplementary Figure S1) mutants which have been reported to have defective LOS biosynthesis were also served as controls. The result indicates that $\Delta 2318$ and $\Delta 2319$ mutants exhibited accumulation of LOS-III and deficiency of LOS-IV. The 2D-TLC profile of the complementation strains $(\Delta 2318:: 2318$ and $\Delta 2319:: 2319)$ were restored to that of wild type. Although LOS-IV deficiency of a mmar_2319 transposon mutant has been demonstrated in previous studies (van der Woude et al., 2012; Alibaud et al., 2014), the role of this gene in LOS synthesis was confirmed by deletion and complementation in this study. These data suggested that these two genes were responsible for LOS synthesis.

\section{Phenotypic Confirmation Using Deletion and Complementation Strains}

First, deletion of mmar_2318 or mmar_2319 did not significantly affect the growth rate at $32^{\circ} \mathrm{C}$ and $20^{\circ} \mathrm{C}$ [Supplementary Figure S2 and (Solomon et al., 2003)], indicating that the attenuation of these two mutants were not due to in vitro growth defect. The mmar_2318 and mmar_2319 deletion and complementation strains exhibited the expected attenuation and virulence phenotypes in the Dictyostelium phagocytotic plaque assay (Figure 4A), confirming the results observed with the

TABLE 2 | Transposon mutants permissive for Dictyostelium growth.

\begin{tabular}{|c|c|c|c|}
\hline Mutant No. & $\begin{array}{l}\text { Genes inserted by } \\
\text { transposon }\end{array}$ & Putative function & $\begin{array}{l}\text { Homologs in M. tuberculosis } \\
\text { H37Rv }\end{array}$ \\
\hline $8-\mathrm{H} 11$ & mmar_0328 & Secreted antigen $85-C$ & FpbC \\
\hline 12-E12 & mmar_0838 & Hypothetical protein & \\
\hline 14-C12 & mmar_0932 & PPE family protein & PPE24 \\
\hline $14-\mathrm{F} 4$ & mmar_1514 & PPE family protein, PPE51_1 & PPE51 \\
\hline 12-B3, 12-E1 & $\begin{array}{l}\text { Upstream of } \text { mmar_}_{-} 1594 \\
\text { and mmar_1595 }\end{array}$ & $\begin{array}{l}\text { mmar_1594: PE_PGRS family protein } \\
\text { mmar_1595:O-methyltransferase }\end{array}$ & $\begin{array}{l}\text { PE_PGRS55 } \\
\text { Rv3767c }\end{array}$ \\
\hline $15-B 4$ & mmar_1639 & PPE family protein & PPE8 \\
\hline $12-C 12$ & mmar_1887 & Conserved transmembrane transport protein & \\
\hline 4-B11, 4-C3, 16-G9 & mmar_2313 & IosA, glycosyltransferase & Rv1500 \\
\hline 14-D5, 2-A3, 4-E9, 15-D8 & mmar_2318 & Conserved hypothetical protein & Rv1502 \\
\hline 16-F5, 11-G3, 2-E6 & mmar_2319 & Conserved hypothetical transmembrane protein & \\
\hline 2-C10, 2-G4 & mmar_2320 & wecE, pyridoxal phosphate-dependent enzyme & \\
\hline $10-\mathrm{A} 11$ & mmar_2323 & Conserved hypothetical transmembrane protein & \\
\hline 13-B8 & mmar_2353 & UDP-glycosyltransferase & Rv1524 \\
\hline $12-E 11$ & Upstream of mmar_2684 & PPE family protein & PPE32 \\
\hline 18-G4 & mmar_3183 & Hypothetical alanine rich protein & \\
\hline 18-D7 & Upstream of mmar_3375 & Conserved hypothetical protein & \\
\hline $17-\mathrm{A} 5,18-\mathrm{H} 5,12-\mathrm{A} 1$ & mmar_4263 & Conserved hypothetical protein & \\
\hline 13-G8 & mmar_4621 & PPE family protein & PPE8 \\
\hline $5-\mathrm{H} 1$ & mmar_4630 & Membrane-bound C-5 sterol desaturase & Erg3 \\
\hline
\end{tabular}




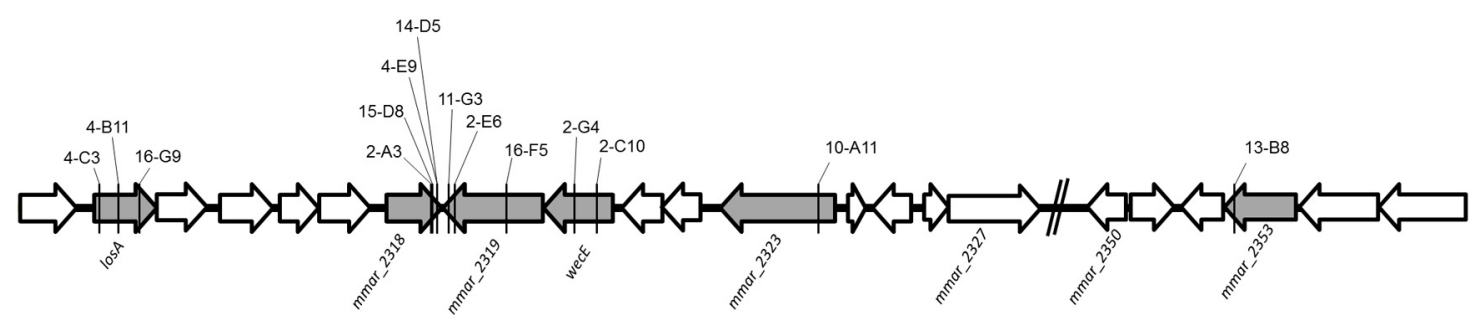

FIGURE 2 | The transposon insertion sites of mutants within lipooligosaccharide (LOS) synthesis locus. The six genes with gray color (losA, mmar_2318, mmar_2319, wecE, mmar_2323 and mmar_2353) within LOS synthesis locus had transposon insertions in different sites. The solid line indicates the transposon insertion.

A

Wild type
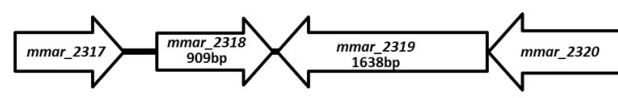

$\Delta 2318$

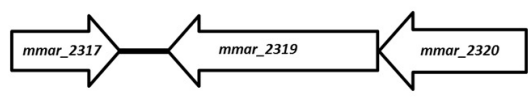

$\Delta 2319$

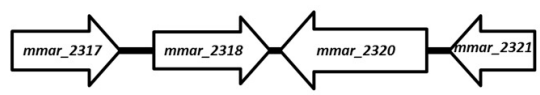

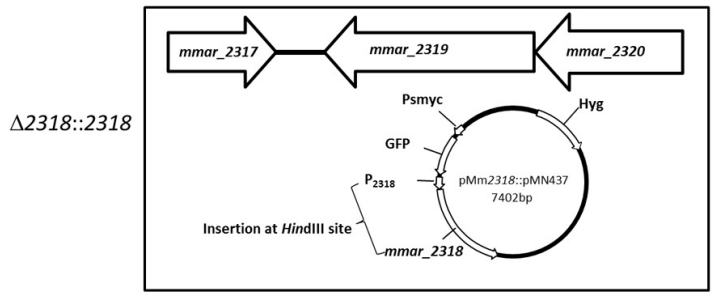

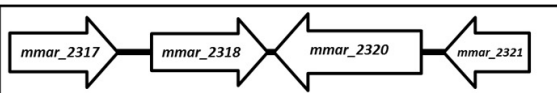

$\Delta 2319:: 2319$

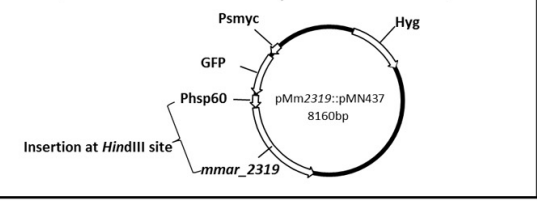

B
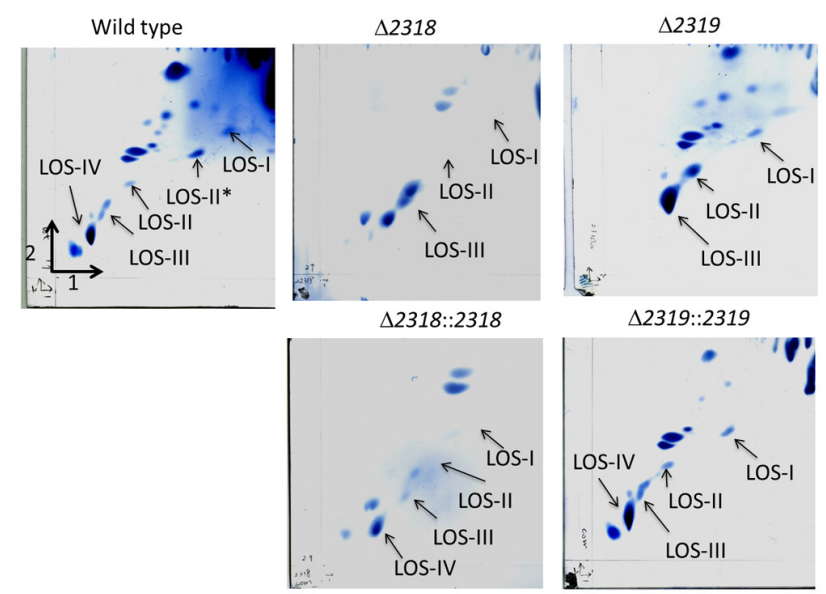

FIGURE 3 | The 2D-TLC profile of the polar lipid of $M$. marinum wild-type, deletion mutants and complementation strains. (A) The gene alignment of mmar_2318 and mmar_2319 deletion mutants and complementation strains. The $\Delta 2318$ and $\Delta 2319$ deletion mutants were created by unmarked deletion of mmar_2318 and mmar_2319, respectively. pMm2318::pMN437 and pMm2319::pMN437 plasmids were used to create the epichromosomal complementation strains $\Delta 2318:: 2318$ and $\Delta 2319:: 2319$, respectively. (B) The 2D-TLC profile of the polar lipid of M. marinum. Using 2D-TLC, extracted M. marinum polar lipids were separated by chloroform/methanol/water (60:30:6, v/v/v) in the first direction and by chloroform/acetic acid/methanol/water (40:25:3:6, v/v/v/v) in the second direction. The plates were charred with ceric ammonium molybdate. Accumulation of LOS-III and deficiency of LOS-IV were observed in the $\Delta 2318$ and $\Delta 2319$ mutants. The 2D-TLC lipid composition profiles of the $\Delta 2318:: 2318$ and $\Delta 2319:: 2319$ complementation strains were restored to that of the wild-type strain. 


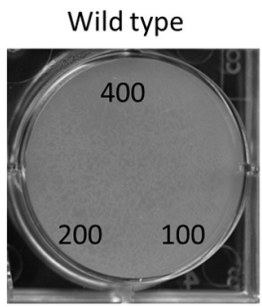

Wild type /pMN437
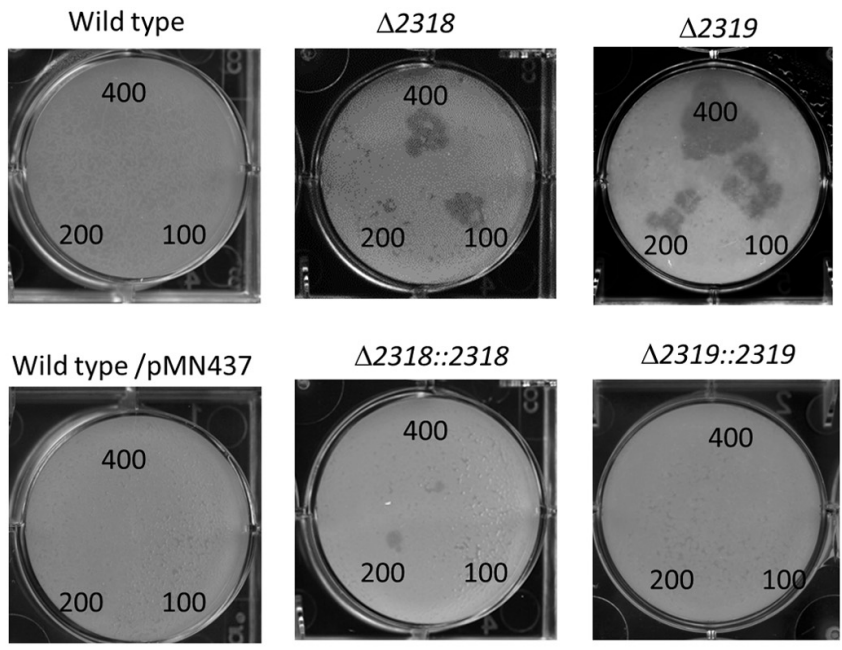

M. smegmatis $\mathrm{mc}^{2} 155$
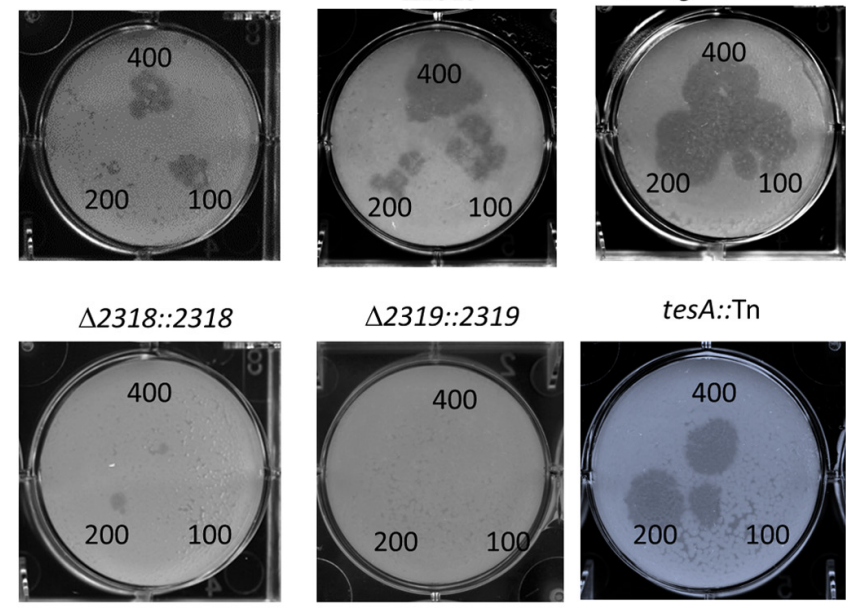

tesA::Tn

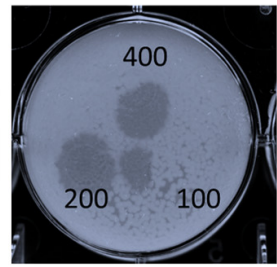

B

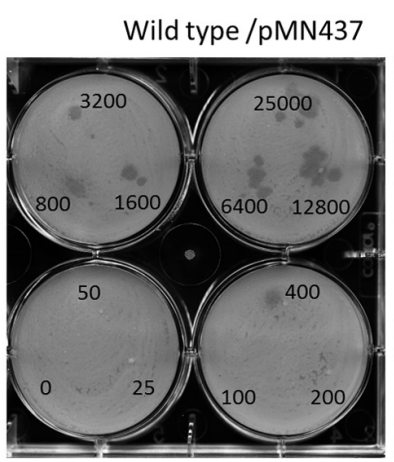

$\Delta 2318$

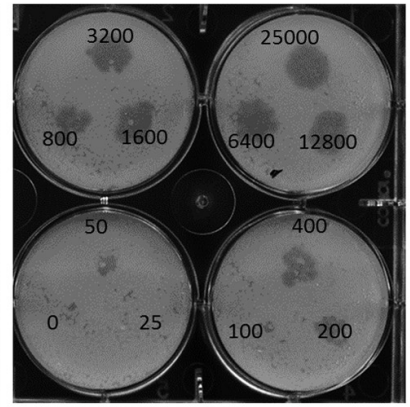

$\Delta 2319$
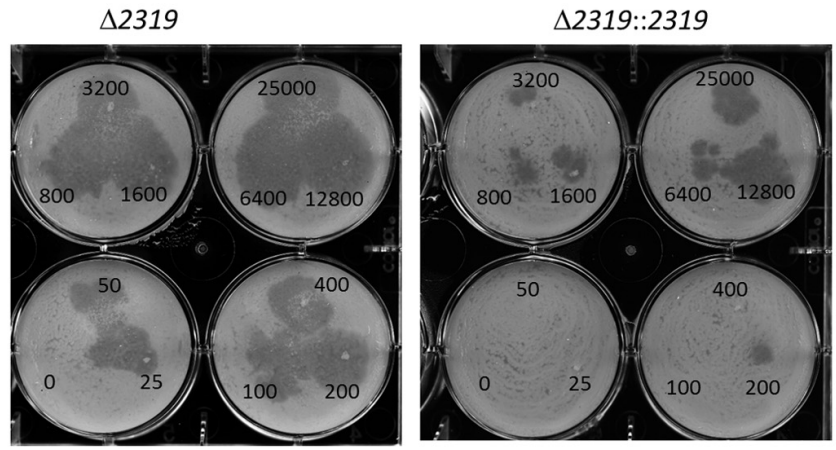

FIGURE 4 | Phenotypic confirmation and quantitative analysis of deletion mutants and complementation strains. (A) The Dictyostelium phagocytosis plaques on bacterial lawn with the wild-type, deletion, and complementation strains. A total of 400, 200 , or 100 Dictyostelium cells could form a clear phagocytosis plaque on a bacterial lawn with $\Delta 2318$ and $\Delta 2319$ mutants but not with the wild-type, $\Delta 2318:: 2318$ and $\Delta 2319:: 2319$ strains. $M$. smegmatis mc ${ }^{2} 155$ and tesA::Tn mutant (known as an avirulent M. marinum mutant) were served as controls. Comparable results were observed in wild type vs. wild type/pMN437, demonstrating that the transfer of pMN437 into M. marinum did not affect phagocytic plaque formation. (B) Quantitative analysis of virulence of wild-type, deletion, and complementation strains. Different amounts of Dictyostelium (0-25000 cells) were used to quantify the virulence of the $M$. marinum wild-type strain, the deletion mutants ( $\Delta 2318$ and $\Delta 2319)$, and the complementation strains $(\Delta 2318:: 2318$ and $\Delta 2319:: 2319)$. Fifty cells and twenty-five Dictyostelium cells could form a clear phagocytic plaque on bacterial lawn with the $\Delta 2318$ and $\Delta 2319$ mutants, respectively, but not with the wild-type, $\Delta 2318:: 2318$ and $\Delta 2319:: 2319$ strains. The virulence phenotype was restored (>400 cells) in the complementation strain.

transposon mutants. Meanwhile, a tes $A$ transposon mutant with attenuation phenotype which has been reported previously (Alibaud et al., 2011) was generated and served as a control
(Figure 4A). Furthermore, we also used different cell numbers of Dictyostelium to quantify the virulence of the wild-type, deletion mutant, and complementation strains. In presence of 

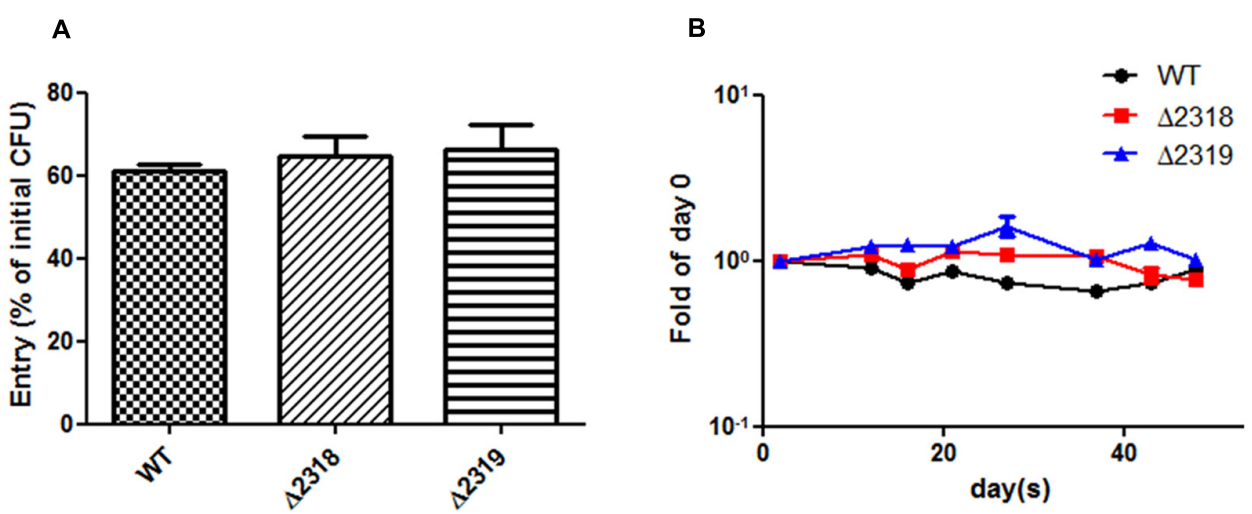

FIGURE 5 | Entry and growth of $\boldsymbol{M}$. marinum inside Dictyostelium. (A) The entry of M. marinum wild-type, $\Delta 2318$ and $\Delta 2319$ into Dictyostelium. The bacteria numbers inside Dictyostelium cells on $2 \mathrm{~h}$ post infection at $\mathrm{MOI}=10$ were determined. Entry was represented as the percentage of entry CFU versus initial CFU of three independent experiments. The two deletion mutants ( $\Delta 2318$ and $\Delta 2319)$ had no significantly different entry rate in comparison with wild type. Data from three independent experiments are presented as the mean \pm SEM of the \% of initial CFU. (B) Growth kinetics of the M. marinum wild-type, $\Delta 2318$ and $\Delta 2319$ strain inside Dictyostelium. The bacteria numbers inside Dictyostelium on different hours $(2,12,16,21,26,37,43,48)$ post infection at $M O I=10$ were determined. Data from three independent experiments are presented as the mean \pm SEM of the fold of initial entering bacteria number.

A $\quad$ J774a.1

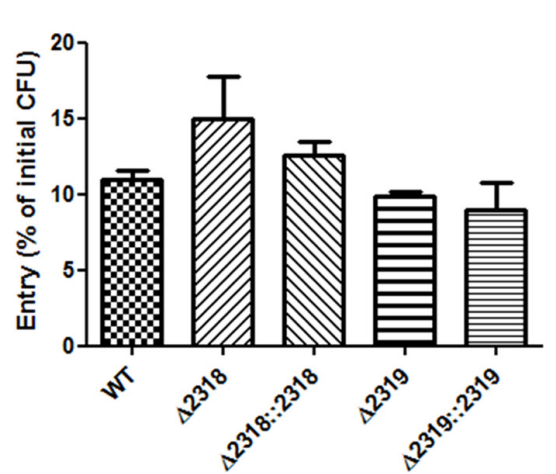

D

THP-1

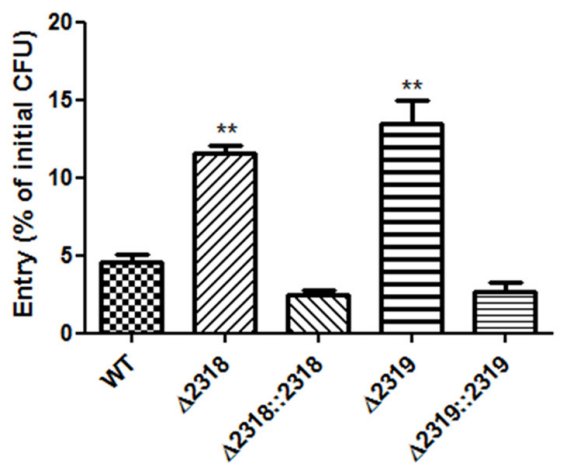

B J774a.1

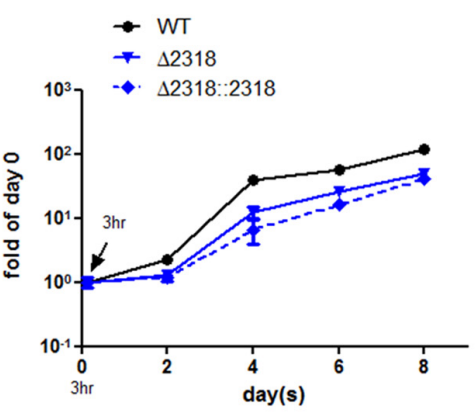

E THP-1
C

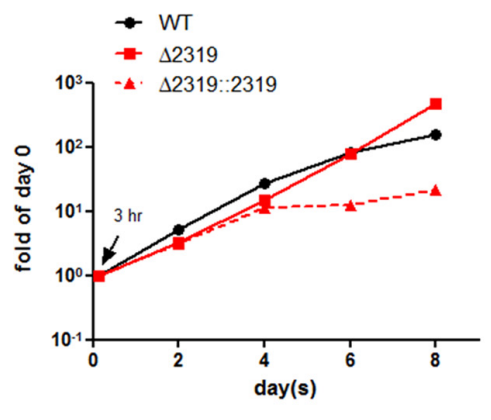

FIGURE 6 | Entry and growth of $\boldsymbol{M}$. marinum inside macrophages. The entry of M. marinum wild-type, $\Delta 2318, \Delta 2319, \Delta 2318:: 2318$, and $\Delta 2319:: 2319$ strains into macrophages. The bacteria numbers inside macrophage cells on day 0 ( $3 \mathrm{~h}$ post infection) at $\mathrm{MOI}=10$ were determined. Entry was represented as the percentage of entry CFU vs. initial CFU of three independent experiments. No significant differences were noted among the wild-type strain, the deletion mutants ( $\Delta 2318$ and $\Delta 2319$ ), and the complementation strains ( $\Delta 2318:: 2318$ and $\Delta 2319:: 2319$ ) into J774a.1 (A) but the recovered bacteria number of two deletion mutants were significantly higher than wild-type strain into THP-1 (D). Data from three independent experiments are presented as the mean \pm SEM of the $\%$ of initial CFU. ${ }^{* *} p<0.001$. Growth kinetics of the M. marinum wild-type, $\Delta 2318, \Delta 2319, \Delta 2318:: 2318$, and $\Delta 2319:: 2319$ strain inside macrophages. The bacteria numbers inside $\mathbf{J} 774 \mathrm{a} .1$ (B,C) or THP-1 $\mathbf{E}$ ) cells on days $0(3 \mathrm{~h}), 2,4,6$, and 8 days at $\mathrm{MOI}=1$ were determined. Data from three independent experiments are presented as the mean \pm SEM of the fold of initial entering bacteria number. 
wild-type $M$. marinum, phagocytic plaque formation exhibited a dose-dependent response to the Dictyostelium cell number, with plaque formation detected in the presence of $>400$ amoeba (Figure 4B). Deletion of mmar_2318 or mmar_2319 attenuated the virulence to Dictyostelium (with plaques observed with 50 amoeba cells and as few as 25 amoeba cells, respectively), whereas two complementation strains restored the virulence to Dictyostelium ( $>400$ cells) to a level similar to that observed in wild type.

The loss of LOS results in rough bacterial colony morphology (Ren et al., 2007; Sarkar et al., 2011; van der Woude et al., 2012). The $\Delta 2318$ and $\Delta 2319$ mutants showed a rough phenotype and bigger colonies size than wild type (Supplementary Figure S3). Colonies morphology and size of complementation strains $(\Delta 2318:: 2318$ and $\Delta 2319:: 2319)$ were restored as those of wild type (Supplementary Figure S3).

\section{Deletion of mmar_2318 or $\mathbf{m m a r} 2319$ did not Affect the Entry and Replication Inside Dictyostelium}

Deletion and complementation confirmed mmar_2318 and mmar_2319 were contributed to virulence toward Dictyostelium. We further examined the ability of the $\Delta 2318$ and $\Delta 2319$ strains to enter and replicate inside cells of Dictyostelium. The results showed that the number of CFU recovered from Dictyostelium was not significantly different between wild type and mutants $(\Delta 2318$ and $\Delta 2319)$ (Figure 5A). The growth rate of $\Delta 2318$ or $\Delta 2319$ mutants inside Dictyostelium was subsequently monitored, as shown in Figure 5B, the growth rate of wild type and mutants were not significantly different, either. These results indicated that deletion of mmar_2318 or mmar_2319 did not affect the entry and replication inside Dictyostelium.

\section{Increased Entry to THP-1 Macrophage Cells in the Deletion Mutants}

Besides observations in Dictyostelium, the ability of the $\Delta 2318$ and $\Delta 2319$ strains to enter and replicate inside cells of macrophage cell line, J774a.1 (murine) and THP-1 (human), were examined. After incubation of bacteria and macrophage cell lines for $3 \mathrm{~h}$ at $32^{\circ} \mathrm{C}$, the cultures were then treated with gentamicin to remove extracellular bacteria, and intracellular bacteria were quantified by lysing the infected cultures and plating onto $7 \mathrm{H} 11$ agar plates. The results indicated that the entry abilities of $\Delta 2318$ and $\Delta 2319$ mutants were not affected in J774a.1 (Figure 6A), but the number of CFU recovered from THP-1 cell line infected with the $\Delta 2318$ or $\Delta 2319$ mutants was significantly higher than that infected with the wild-type strain (Figure 6D). We also examined the subsequent growth of $\Delta 2318$ and $\Delta 2319$ mutants inside these two macrophage cell lines. The results demonstrated that the deletion mutants both exhibited growth rates similar to wild type and could replicate inside macrophages during the course of infection (Figures 6B,C,E). These data suggest that deletion of mmar_2318 or mmar_2319 did not affect the ability of the bacteria to replicate within macrophages.

\section{DISCUSSION}

The complete genome of the $M$. marinum $M$ strain is approximately $6.6 \mathrm{Mb}$ in size and is composed of 5568 open reading frames (ORFs) (accession number: CP000854.1). Our mutant library includes a collection of 1728 transposon insertions. The insertion sites of 30 Dictyostelium-permissive mutants (in the present work), as well as those of another 17 randomly selected mutants (Table 3 ), were unique, and the transposons of these 47 mutants were collectively located in 36 different loci (Tables 2 and 3). These results indicate that the library has good diversity. However, real coverage is difficult to estimate given that insertions close to an operon can cause phenotypic changes due to polar effects on gene expression. Additionally, essential genes (estimated as $5-20 \%$ of bacterial genomes) (Gerdes et al., 2003; Salama et al., 2004; Liberati et al., 2006), although less likely to be specific virulence genes, would not be identified by transposon mutagenesis. Therefore, we expect that our mutant library is not saturated with respect to candidate loci, and our screen and library are expected to have missed multiple loci.

Alibaud et al. (2011) first used Dictyostelium as a screening model to identify virulent genes within $M$. marinum in 2011. These researchers screened only 275 transposon mutants of the M. marinum $M$ strain (Alibaud et al., 2011). Our work adopted the same screening strategy, but we screened a larger number of mutants (1728

TABLE 3 | Seventeen randomly selected transposon mutants for diversity check.

\begin{tabular}{|c|c|c|}
\hline Mutant No. & $\begin{array}{l}\text { Genes inserted } \\
\text { by transposon }\end{array}$ & Putative function \\
\hline 1 & mmar_1131 & Hypothetical protein \\
\hline 2 & mmar_1485 & $\begin{array}{l}\text { Membrane-associated } \\
\text { phospholipase C } 2 \text { PlcB_2 }\end{array}$ \\
\hline 3 & mmar_3589 & Prophage integrase \\
\hline 4 & mmar_2513 & Hypothetical protein \\
\hline $6-F 5$ & mmar_4264 & Conserved hypothetical protein \\
\hline $6-\mathrm{F7}$ & mmar_3382 & $\begin{array}{l}\text { Conserved hypothetical membrane } \\
\text { protein }\end{array}$ \\
\hline 6-F10, 10-B11 & \multicolumn{2}{|c|}{$\begin{array}{l}\text { Not similar with sequences of } M \text {. marinum } M \text { (may be the same } \\
\text { gene but different insertion sites) }\end{array}$} \\
\hline $6-G 2$ & \multicolumn{2}{|c|}{ Not similar with sequences of $M$. marinum $M$} \\
\hline $6-G 3$ & \multicolumn{2}{|c|}{ Not similar with sequences of $M$. marinum M } \\
\hline 9-D1 & mmar_5435 & $\begin{array}{l}\text { Conserved hypothetical alanine and } \\
\text { glycine rich protein }\end{array}$ \\
\hline 9-D12 & mmar_2687 & $\begin{array}{l}\mathrm{Mg}^{2+} \text { transport p-type ATPase C } \\
\text { MgtC }\end{array}$ \\
\hline 9-E2 & mmar_3612 & $\begin{array}{l}\text { Metal cation transporter p-type } \\
\text { ATPase }\end{array}$ \\
\hline 9-E5 & mmar_0932 & PPE family protein \\
\hline 9-E6 & \multicolumn{2}{|c|}{ Not similar with sequences of $M$. marinum $\mathrm{M}$} \\
\hline 10-B9 & mmar_0599 & $\begin{array}{l}\text { Conserved hypothetical secreted } \\
\text { protein }\end{array}$ \\
\hline $10-\mathrm{C} 2$ & mmar_3414 & $\begin{array}{l}\text { Hypothetical alanine and proline } \\
\text { rich protein }\end{array}$ \\
\hline
\end{tabular}


isolates, corresponding to our entire mutant library) and used a distinct strain of $M$. marinum. In this study, we used a clinical isolate, the $M$. marinum NTUH-M6094 strain, to construct the mutant library. When assessing the library diversity, we also found that 5/36 (13.8\%) of the transposon interrupted loci were not obvious homologs of sequences from the sequenced $M$. marinum $M$ strain (Table 3). This result suggests that genetic heterogeneity exists in M. marinum isolates from different regions and/or sources.

In this study, we used a Dictyostelium phagocytotic plaque model system to screen a $M$. marinum transposon mutant library, identifying 20 genes with roles in virulence. Among these 20 genes, some loci [e.g., $\operatorname{los} A$, wecE, transmembrane transporter protein and proline-proline-glutamic acid (PPE) family related genes] were previously reported to be associated with virulence, macrophage resistance, biofilm formation, or LOS synthesis in Mycobacterium spp. (Okkels et al., 2003; Burguiere et al., 2005; Domenech et al., 2005; McEvoy et al., 2009; Brodin et al., 2010; Alibaud et al., 2011; Dong et al., 2012; Wang et al., 2013). The results of our screen were therefore consistent with data from other studies. We also found several genes that were not previously identified as virulence genes in the literature, including 12 loci with homologs in M. tuberculosis (Table 2). Our results implicate these loci in $M$. tuberculosis pathogenesis. However, the actual role of these genes in M. marinum and $M$. tuberculosis will require confirmation; characterization of these loci will be reported elsewhere.

In our study, six genes (losA, mmar_2318, mmar_2319, wecE, mmar_2323, and mmar_2353) located within the predicted LOS synthesis locus were identified. The effects on the polar lipid 2D-TLC profile after transposon knockout of losA, mmar_2319, wecE, and mmar_2353 were previously reported (van der Woude et al., 2012; Alibaud et al., 2014) and confirmed by this study (Figure $\mathbf{3 B}$ and Supplementary Figure S1). In this study, we focused on the role of mmar_2318 and mmar_2319 on LOS synthesis and virulence in Dictyostelium and macrophages. Although deletion of mmar_2318 or mmar_2319 both revealed deficiency of LOS-IV, prominent phagocytosis plaques and bigger colonies were observed in $\Delta 2319$ mutant compared with $\Delta 2318$ mutant. This may be due to different degrees of LOS-III accumulation or unknown effects other than impairment of LOS after deletion of mmar_2318 or mmar_2319.

Our result confirmed $\Delta 2318$ and $\Delta 2319$ mutants also reduced virulence toward Dictyostelium. To dissect the virulence toward amoebae contributed by mmar_2318 and mmar_2319, we also examined the ability of the $\Delta 2318$ and $\bar{\Delta} 2319$ mutants to enter and replicate inside cells of Dictyostelium. As shown in Figure 5, no matter entry or replication inside Dictyostelium, there were no significant difference between wildtype and two deletion mutants. These results indicated that the reduced virulence toward Dictyostelium after deletion of mmar_2318 or mmar_2319 was not resulted from affecting the initial entry and survival inside cells. These two genes might be through other mechanisms to inhibit Dictyostelium growth.

In 2012, van der Woude et al. (2012) found that a $M$. marinum wecE transposon mutant was hyper-virulent to zebrafish, but our study demonstrated that a wecE::Tn mutant was permissive for Dictyostelium growth. This difference is potentially attributed to the facts that zebrafish and Dictyostelium are different species and zebrafish is a more complex model. These results suggested that the attenuation of mutants identified by using Dictyostelium screening should be confirmed in a more complex host. A recent study published by Alibaud et al. (2014) examined the phagocytosis of a mmar_2319 transposon mutant by murine macrophage J774a.1 cells. This study is consistent with our observation that the phagocytosis rate of the mmar_2319 deletion mutant was similar to that of the wild-type strain in J774a.1. But in this study, we observed the entry ability of deletion mutants ( $\Delta 2318$ or $\Delta 2319)$ was significantly higher than that of wild type into another macrophage cell line, THP-1. This may be due to different host origins that these two cell lines were isolated from. The increased entry into THP-1 cell after deletion of mmar_2318 and mmar_2319 might explain the hyper-virulence to zebrafish of wecE mutant which also revealed accumulation of LOS-III and deficiency of LOS-IV. However, the virulence of $\triangle 2318$ and $\Delta 2319$ mutants to zebrafish or mammalian hosts requires more investigations.

\section{CONCLUSION}

We identified a new gene, mmar_2318, involved the LOS biosynthesis. M. marinum mmar_2318 and mmar_2319 were both responsible for virulence toward Dictyostelium; deletion of mmar_2318 and mmar_2319 increased entry ability into THP1 cell but not affected the replication inside Dictyostelium and macrophages.

\section{ACKNOWLEDGMENTS}

We thank Dr. Mei-Yu Chen (Institute of Biochemistry and Molecular Biology, National Yang-Ming University, Taipei) for kindly providing a Dictyostelium strain. This study was supported by grants from the Ministry of Science and Technology, the National Taiwan University, the National Taiwan University Hospital and the Liver Disease Prevention and Treatment Research Foundation in Taiwan.

\section{SUPPLEMENTARY MATERIAL}

The Supplementary Material for this article can be found online at: http://journal.frontiersin.org/article/10.3389/fmicb. 2015.01458 


\section{REFERENCES}

Adams, K. N., Takaki, K., Connolly, L. E., Wiedenhoft, H., Winglee, K., Humbert, O., et al. (2011). Drug tolerance in replicating mycobacteria mediated by a macrophage-induced efflux mechanism. Cell 145, 39-53. doi: 10.1016/j.cell.2011.02.022

Alexander, D. C., Jones, J. R., Tan, T., Chen, J. M., and Liu, J. (2004). PimF, a mannosyltransferase of mycobacteria, is involved in the biosynthesis of phosphatidylinositol mannosides and lipoarabinomannan. J. Biol. Chem. 279, 18824-18833. doi: 10.1074/jbc.M400791200

Alibaud, L., Pawelczyk, J., Gannoun-Zaki, L., Singh, V. K., Rombouts, Y., Drancourt, M., et al. (2014). Increased phagocytosis of Mycobacterium marinum mutants defective in lipooligosaccharide production: a structure-activity relationship study. J. Biol. Chem. 289, 215-228. doi: 10.1074/jbc.M113.525550

Alibaud, L., Rombouts, Y., Trivelli, X., Burguiere, A., Cirillo, S. L., Cirillo, J. D., et al. (2011). A Mycobacterium marinum TesA mutant defective for major cell wallassociated lipids is highly attenuated in Dictyostelium discoideum and zebrafish embryos. Mol. Microbiol. 80, 919-934. doi: 10.1111/j.1365-2958.2011.07618.x

Arafah, S., Kicka, S., Trofimov, V., Hagedorn, M., Andreu, N., Wiles, S., et al. (2013). Setting up and monitoring an infection of Dictyostelium discoideum with mycobacteria. Methods Mol. Biol. 983, 403-417. doi: 10.1007/978-1-62703302-2_22

Bardarov, S., Kriakov, J., Carriere, C., Yu, S., Vaamonde, C., McAdam, R. A., et al. (1997). Conditionally replicating mycobacteriophages: a system for transposon delivery to Mycobacterium tuberculosis. Proc. Natl. Acad. Sci. U.S.A. 94, 1096110966. doi: 10.1073/pnas.94.20.10961

Behar, S. M., Divangahi, M., and Remold, H. G. (2010). Evasion of innate immunity by Mycobacterium tuberculosis: is death an exit strategy? Nat. Rev. Microbiol. 8, 668-674. doi: 10.1038/nrmicro2387

Brodin, P., Poquet, Y., Levillain, F., Peguillet, I., Larrouy-Maumus, G., Gilleron, M., et al. (2010). High content phenotypic cell-based visual screen identifies Mycobacterium tuberculosis acyltrehalose-containing glycolipids involved in phagosome remodeling. PLoS Pathog. 6:e1001100. doi: 10.1371/journal.ppat.1001100

Burguiere, A., Hitchen, P. G., Dover, L. G., Kremer, L., Ridell, M., Alexander, D. C., et al. (2005). LosA, a key glycosyltransferase involved in the biosynthesis of a novel family of glycosylated acyltrehalose lipooligosaccharides from Mycobacterium marinum. J. Biol. Chem. 280, 42124-42133. doi: 10.1074/jbc.M507500200

Choi, K. P., Bair, T. B., Bae, Y. M., and Daniels, L. (2001). Use of transposon Tn5367 mutagenesis and a nitroimidazopyran-based selection system to demonstrate a requirement for $f b i A$ and $f b i B$ in coenzyme $\mathrm{F}_{420}$ biosynthesis by Mycobacterium bovis BCG. J. Bacteriol. 183, 7058-7066. doi: 10.1128/JB.183.24.7058-7066.2001

Chun, K. T., Edenberg, H. J., Kelley, M. R., and Goebl, M. G. (1997). Rapid amplification of uncharacterized transposon-tagged DNA sequences from genomic DNA. Yeast 13, 233-240. doi: 10.1002/(SICI)1097-0061(19970315)13:3<233::AID-YEA88> 3.3.CO;2-5

Cosson, P., Zulianello, L., Join-Lambert, O., Faurisson, F., Gebbie, L., Benghezal, M., et al. (2002). Pseudomonas aeruginosa virulence analyzed in a Dictyostelium discoideum host system. J. Bacteriol. 184, 3027-3033. doi: 10.1128/JB.184.11.3027-3033.2002

Daffe, M. (1991). Further stereochemical studies of phthiocerol and phenol phthiocerol in mycobacteria. Res. Microbiol. 142, 405-410. doi: 10.1016/09232508(91)90110-V

Daffe, M., and Draper, P. (1998). The envelope layers of mycobacteria with reference to their pathogenicity. Adv. Microb. Physiol. 39, 131-203. doi: 10.1016/S0065-2911(08)60016-8

Davis, J. M., and Ramakrishnan, L. (2009). The role of the granuloma in expansion and dissemination of early tuberculous infection. Cell 136, 37-49. doi: 10.1016/j.cell.2008.11.014

Domenech, P., Reed, M. B., and Barry, C. E. III. (2005). Contribution of the Mycobacterium tuberculosis $\mathrm{MmpL}$ protein family to virulence and drug resistance. Infect. Immun. 73, 3492-3501. doi: 10.1128/IAI.73.6. 3492-3501.2005

Dong, D., Wang, D., Li, M., Wang, H., Yu, J., Wang, C., et al. (2012). PPE38 modulates the innate immune response and is required for Mycobacterium marinum virulence. Infect. Immun. 80, 43-54. doi: 10.1128/IAI.05249-11
Gerdes, S. Y., Scholle, M. D., Campbell, J. W., Balazsi, G., Ravasz, E., Daugherty, M. D., et al. (2003). Experimental determination and system level analysis of essential genes in Escherichia coli MG1655. J. Bacteriol. 185, 5673-5684. doi: 10.1128/JB.185.19.5673-5684.2003

Gilleron, M., Vercauteren, J., and Puzo, G. (1993). Lipooligosaccharidic antigen containing a novel C4-branched 3,6-dideoxy-alpha-hexopyranose typifies Mycobacterium gastri. J. Biol. Chem. 268, 3168-3179.

Hagedorn, M., Rohde, K. H., Russell, D. G., and Soldati, T. (2009). Infection by tubercular mycobacteria is spread by nonlytic ejection from their amoeba hosts. Science 323, 1729-1733. doi: 10.1126/science.1169381

Hagedorn, M., and Soldati, T. (2007). Flotillin and $\mathrm{RacH}$ modulate the intracellular immunity of Dictyostelium to Mycobacterium marinum infection. Cell Microbiol. 9, 2716-2733. doi: 10.1111/j.1462-5822.2007.00993.x

Harriff, M., and Bermudez, L. E. (2009). Environmental amoebae and mycobacterial pathogenesis. Methods Mol. Biol. 465, 433-442. doi: 10.1007/9781-59745-207-6_28

Hilbi, H., Weber, S. S., Ragaz, C., Nyfeler, Y., and Urwyler, S. (2007). Environmental predators as models for bacterial pathogenesis. Environ. Microbiol. 9, 563-575. doi: 10.1111/j.1462-2920.2007.01238.x

Hodgkinson, J. W., Ge, J. Q., Grayfer, L., Stafford, J., and Belosevic, M. (2012). Analysis of the immune response in infections of the goldfish (Carassius auratus L.) with Mycobacterium marinum. Dev. Comp. Immunol. 38, 456-465. doi: 10.1016/j.dci.2012.07.006

Hunter, S. W., Fujiwara, T., Murphy, R. C., and Brennan, P. J. (1984). $\mathrm{N}$-acylkansosamine. A novel $\mathrm{N}$-acylamino sugar from the trehalose-containing lipooligosaccharide antigens of Mycobacterium kansasii. J. Biol. Chem. 259, 9729-9734.

Hunter, S. W., Murphy, R. C., Clay, K., Goren, M. B., and Brennan, P. J. (1983). Trehalose-containing lipooligosaccharides. A new class of species-specific antigens from Mycobacterium. J. Biol. Chem. 258, 10481-10487.

Jarlier, V., and Nikaido, H. (1990). Permeability barrier to hydrophilic solutes in Mycobacterium chelonei. J. Bacteriol. 172, 1418-1423.

Jules, M., and Buchrieser, C. (2007). Legionella pneumophila adaptation to intracellular life and the host response: clues from genomics and transcriptomics. FEBS Lett. 581, 2829-2838. doi: 10.1016/j.febslet.2007.05.026

Karakousis, P. C., Bishai, W. R., and Dorman, S. E. (2004). Mycobacterium tuberculosis cell envelope lipids and the host immune response. Cell Microbiol. 6, 105-116. doi: 10.1046/j.1462-5822.2003.00351.x

Larsen, M. H., Biermann, K., Tandberg, S., Hsu, T., and Jacobs, W. R. Jr. (2007). Genetic manipulation of Mycobacterium tuberculosis. Curr. Protoc. Microbiol. Chapter 10, Unit10A12.

Li, Z., Dugan, A. S., Bloomfield, G., Skelton, J., Ivens, A., Losick, V., et al. (2009). The amoebal MAP kinase response to Legionella pneumophila is regulated by DupA. Cell Host Microbe 6, 253-267. doi: 10.1016/j.chom.2009.08.005

Liberati, N. T., Urbach, J. M., Miyata, S., Lee, D. G., Drenkard, E., Wu, G., et al. (2006). An ordered, nonredundant library of Pseudomonas aeruginosa strain PA14 transposon insertion mutants. Proc. Natl. Acad. Sci. U.S.A. 103, 2833-2838. doi: 10.1073/pnas.0511100103

McEvoy, C. R., van Helden, P. D., Warren, R. M., and Gey van Pittius, N. C. (2009). Evidence for a rapid rate of molecular evolution at the hypervariable and immunogenic Mycobacterium tuberculosis PPE38 gene region. BMC Evol. Biol. 9:237. doi: 10.1186/1471-2148-9-237

McNeil, M., Chatterjee, D., Hunter, S. W., and Brennan, P. J. (1989). Mycobacterial glycolipids: isolation, structures, antigenicity, and synthesis of neoantigens. Methods Enzymol. 179, 215-242. doi: 10.1016/0076-6879(89) 79123-0

Mehta, P. K., Pandey, A. K., Subbian, S., El-Etr, S. H., Cirillo, S. L., Samrakandi, M. M., et al. (2006). Identification of Mycobacterium marinum macrophage infection mutants. Microb. Pathog. 40, 139-151. doi: 10.1016/j.micpath.2005.12.002

Neyrolles, O., and Guilhot, C. (2011). Recent advances in deciphering the contribution of Mycobacterium tuberculosis lipids to pathogenesis. Tuberculosis (Edinb). 91, 187-195. doi: 10.1016/j.tube.2011.01.002

Okkels, L. M., Brock, I., Follmann, F., Agger, E. M., Arend, S. M., Ottenhoff, T. H., et al. (2003). PPE protein (Rv3873) from DNA segment RD1 of Mycobacterium tuberculosis: strong recognition of both specific T-cell epitopes and epitopes conserved within the PPE family. Infect. Immun. 71, 6116-6123. doi: 10.1128/IAI.71.11.6116-6123.2003 
Pan, Y. J., Lin, T. L., Hsu, C. R., and Wang, J. T. (2011). Use of a Dictyostelium model for isolation of genetic loci associated with phagocytosis and virulence in Klebsiella pneumoniae. Infect. Immun. 79, 997-1006. doi: 10.1128/IAI.00906-10

Parish, T., and Stoker, N. G. (2000). Use of a flexible cassette method to generate a double unmarked Mycobacterium tuberculosis tlyA plcABC mutant by gene replacement. Microbiology 146(Pt 8), 1969-1975. doi: 10.1099/00221287-1468-1969

Pozos, T. C., and Ramakrishnan, L. (2004). New models for the study of Mycobacterium-host interactions. Curr. Opin. Immunol. 16, 499-505. doi: 10.1016/j.coi.2004.05.011

Pukatzki, S., Kessin, R. H., and Mekalanos, J. J. (2002). The human pathogen Pseudomonas aeruginosa utilizes conserved virulence pathways to infect the social amoeba Dictyostelium discoideum. Proc. Natl. Acad. Sci. U.S.A. 99, 31593164. doi: 10.1073/pnas.052704399

Pukatzki, S., Ma, A. T., Revel, A. T., Sturtevant, D., and Mekalanos, J. J. (2007). Type VI secretion system translocates a phage tail spike-like protein into target cells where it cross-links actin. Proc. Natl. Acad. Sci. U.S.A. 104, 15508-15513. doi: 10.1073/pnas.0706532104

Pukatzki, S., Ma, A. T., Sturtevant, D., Krastins, B., Sarracino, D., Nelson, W. C., et al. (2006). Identification of a conserved bacterial protein secretion system in Vibrio cholerae using the Dictyostelium host model system. Proc. Natl. Acad. Sci. U.S.A. 103, 1528-1533. doi: 10.1073/pnas.0510322103

Ren, H., Dover, L. G., Islam, S. T., Alexander, D. C., Chen, J. M., Besra, G. S., et al. (2007). Identification of the lipooligosaccharide biosynthetic gene cluster from Mycobacterium marinum. Mol. Microbiol. 63, 1345-1359. doi: 10.1111/j.13652958.2007.05603.x

Rombouts, Y., Burguiere, A., Maes, E., Coddeville, B., Elass, E., Guerardel, Y., et al. (2009). Mycobacterium marinum lipooligosaccharides are unique caryophyllose-containing cell wall glycolipids that inhibit tumor necrosis factor-alpha secretion in macrophages. J. Biol. Chem. 284, 20975-20988. doi: 10.1074/jbc.M109.011429

Rybniker, J., Wolke, M., Haefs, C., and Plum, G. (2003). Transposition of Tn5367 in Mycobacterium marinum, using a conditionally recombinant mycobacteriophage. J. Bacteriol. 185, 1745-1748. doi: 10.1128/JB.185.5.17451748.2003

Salama, N. R., Shepherd, B., and Falkow, S. (2004). Global transposon mutagenesis and essential gene analysis of Helicobacter pylori. J. Bacteriol. 186, 7926-7935. doi: 10.1128/JB.186.23.7926-7935.2004

Sarkar, D., Sidhu, M., Singh, A., Chen, J., Lammas, D. A., van der Sar, A. M., et al. (2011). Identification of a glycosyltransferase from Mycobacterium marinum involved in addition of a caryophyllose moiety in lipooligosaccharides. J. Bacteriol. 193, 2336-2340. doi: 10.1128/JB.00065-11

Scholz, O., Thiel, A., Hillen, W., and Niederweis, M. (2000). Quantitative analysis of gene expression with an improved green fluorescent protein. p6. Eur. J. Biochem. 267, 1565-1570. doi: 10.1046/j.1432-1327.2000.01170.x

Shin, S. J., Wu, C. W., Steinberg, H., and Talaat, A. M. (2006). Identification of novel virulence determinants in Mycobacterium paratuberculosis by screening a library of insertional mutants. Infect. Immun. 74, 3825-3833. doi: 10.1128/IAI.01742-05

Skeiky, Y. A., and Sadoff, J. C. (2006). Advances in tuberculosis vaccine strategies. Nat. Rev. Microbiol. 4, 469-476. doi: 10.1038/nrmicro1419
Solomon, J. M., Leung, G. S., and Isberg, R. R. (2003). Intracellular replication of Mycobacterium marinum within Dictyostelium discoideum: efficient replication in the absence of host coronin. Infect. Immun. 71, 3578-3586. doi: 10.1128/IAI.71.6.3578-3586.2003

Steinhauer, K., Eschenbacher, I., Radischat, N., Detsch, C., Niederweis, M., and Goroncy-Bermes, P. (2010). Rapid evaluation of the mycobactericidal efficacy of disinfectants in the quantitative carrier test EN 14563 by using fluorescent Mycobacterium terrae. Appl. Environ. Microbiol. 76, 546-554. doi: 10.1128/AEM.01660-09

Tarigo, J., Linder, K., Neel, J., Harvey, S., Remick, A., and Grindem, C. (2006). Reluctant to dive: coelomic effusion in a frog. Vet. Clin. Pathol. 35, 341-344. doi: 10.1111/j.1939-165X.2006.tb00145.x

van der Woude, A. D., Sarkar, D., Bhatt, A., Sparrius, M., Raadsen, S. A., Boon, L., et al. (2012). Unexpected link between lipooligosaccharide biosynthesis and surface protein release in Mycobacterium marinum. J. Biol. Chem. 287, 2041720429. doi: 10.1074/jbc.M111.336461

Vergne, I., Fratti, R. A., Hill, P. J., Chua, J., Belisle, J., and Deretic, V. (2004). Mycobacterium tuberculosis phagosome maturation arrest: mycobacterial phosphatidylinositol analog phosphatidylinositol mannoside stimulates early endosomal fusion. Mol. Biol. Cell 15, 751-760. doi: 10.1091/mbc.E0305-0307

Vlahou, G., Schmidt, O., Wagner, B., Uenlue, H., Dersch, P., Rivero, F., et al. (2009). Yersinia outer protein YopE affects the actin cytoskeleton in Dictyostelium discoideum through targeting of multiple Rho family GTPases. BMC Microbiol. 9:138. doi: 10.1186/1471-2180-9-138

Wang, H., Dong, D., Tang, S., Chen, X., and Gao, Q. (2013). PPE38 of Mycobacterium marinum triggers the cross-talk of multiple pathways involved in the host response, as revealed by subcellular quantitative proteomics. J. Proteome Res. 12, 2055-2066. doi: 10.1021/pr3 01017e

Wong, D., Bach, H., Sun, J., Hmama, Z., and Av-Gay, Y. (2011). Mycobacterium tuberculosis protein tyrosine phosphatase (PtpA) excludes host vacuolar-H+-ATPase to inhibit phagosome acidification. Proc. Natl. Acad. Sci. U.S.A. 108, 19371-19376. doi: 10.1073/pnas.1109 201108

Yang, C. T., Cambier, C. J., Davis, J. M., Hall, C. J., Crosier, P. S., and Ramakrishnan, L. (2012). Neutrophils exert protection in the early tuberculous granuloma by oxidative killing of mycobacteria phagocytosed from infected macrophages. Cell Host Microbe 12, 301-312. doi: 10.1016/j.chom.2012. 07.009

Conflict of Interest Statement: The authors declare that the research was conducted in the absence of any commercial or financial relationships that could be construed as a potential conflict of interest.

Copyright (c) 2016 Chen, Yang, Wu, Lin and Wang. This is an open-access article distributed under the terms of the Creative Commons Attribution License (CC BY). The use, distribution or reproduction in other forums is permitted, provided the original author(s) or licensor are credited and that the original publication in this journal is cited, in accordance with accepted academic practice. No use, distribution or reproduction is permitted which does not comply with these terms. 